\title{
Special working arrangements to allow for care responsibilities in Australia: availability, usage and barriers
}

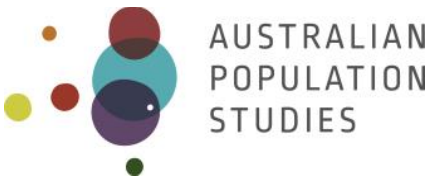

Jeromey Temple* University of Melbourne; ARC Centre of Excellence in Population Ageing Research Briony Dow University of Melbourne; National Ageing Research Institute

Marian Baird University of Sydney; ARC Centre of Excellence in Population Ageing Research

* Corresponding author. Email: Jeromey.Temple@unimelb.edu.au. Address: Melbourne School of Population and Global Health, 207 Bouverie St, University of Melbourne, Melbourne, VIC, 3010.

Paper received 17 January 2019; accepted 10 May 2019; published 27 May 2019

\begin{abstract}
Background

Population ageing is projected to reduce labour force growth and aggregate labour force participation, whilst increasing demand for informal carers. Increasing the labour force participation of Australians who face barriers to employment (including carers) is part of the solution to labour market pressures occurring due to demographic change and may improve the financial wellbeing of carers.
\end{abstract}

\section{Aims}

To examine the availability, usage and barriers to accessing Special Working Arrangements (SWA) to provide care while employed in Australia.

\section{Data and methods}

The 2015 ABS Survey of Disability, Ageing and Carers was used to measure the prevalence of the availability, usage and barriers to SWA to care stratified by carer status and gender.

\section{Results}

About $94 \%$ of workers reported access to at least one type of SWA $(n=25,094)$. Of this group, about $22 \%$ have used SWA to care in the last 6 months. The proportions using SWA to care were highest among primary carers (64\%) followed by other carers (43\%) and non-carers (19\%). Of those who have used SWA, about $15 \%$ wanted to use additional SWA to care in the previous 6 months, but faced barriers in doing so, with higher proportions of primary carers $(24.6 \%)$ and other carers $(21.8 \%)$ reporting barriers. The main barriers faced by employed carers included insufficient paid leave and/or work commitments.

\section{Conclusions}

A range of paid and unpaid arrangements are necessary for carers to combine paid work with their caregiving responsibilities. Labour market legislation and workplace policies should be strengthened to reduce barriers to take up of SWA.

\section{Key words}

Informal care; caring; labour force participation; barriers to employment; special working arrangements 


\section{Introduction}

One aspect of population ageing that has garnered significant attention from policy makers is the implications for the Australian labour market. Both the Productivity Commission and Treasury have noted that population ageing reduces aggregate (i.e. population-level) labour force participation and slows labour force growth (Australian Treasury 2002, 2007, 2010, 2015; Productivity Commission 2005, 2013). Indeed, the rate of growth in labour supply is projected to decline considerably in the next 15 years, relative to the 15 years proceeding (Temple and McDonald 2017). In recent times, international migration has been key to maintaining labour force growth (McDonald 2017). However, a further source of increasing labour supply is to improve labour force attachment among Australians who face barriers to employment or who are under-employed (Temple and McDonald 2017). Increasing labour force attachment of these groups is one part of the solution to declining labour supply growth.

One sizable population that faces significant barriers to labour force participation are Australian carers, numbering approximately 2.7 million people who contribute 60 billion dollars to the economy annually through unpaid work (ABS 2016b; Deloitte Access Economics 2015). With population ageing, the demand for informal care will increase considerably, at the same time that labour supply pressures are occurring in the formal labour market. Importantly, the caregiving role has been shown to effect labour force engagement, with Australian evidence showing that carers are more likely to reduce hours of work, exit the labour market and earn lower levels of income relative to non-carers (Bittman et al. 2007). Many female carers in particular have difficulty in accessing flexible working hours, influencing their decision to leave paid work all together (Austen and Ong 2013). Consistent with this finding, Hill and colleagues find that with the onset of caring responsibilities, flexible working arrangements (such as part time work), significantly reduced the odds of leaving the paid workforce in Australia (Hill et al. 2008). A systematic review of 30 years of international studies of caregiving and employment, specifically cites the importance of the further development of labour market legislation and workplace policies (in tandem with formal support services), to enable carers who wish to work, to be able to do so (Lilly et al. 2007). Australian evidence shows a sizeable proportion of carers wish to work - with about half of those not in paid employment with a preference to be employed (Gray et al. 2008).

\section{Special Working Arrangements and caring in Australia}

Enshrined in the National Employment Standards of Australia's Fair Work Act, carers, people with a disability, those aged 55 years or over and parents with the responsibility to care for a child have the legal right to request flexible working arrangements from their employer (FWO 2018). Although a broad term, flexible working arrangements refer to flexibility in hours of work (e.g. start and finish times), patterns of work (e.g. job sharing or part time work) and location of work (e.g. working from home) (FWO 2018). However, evidence suggests that less than half of all workers are aware of this right (Skinner and Pocock 2014). Moreover, there is no guarantee that the requests for flexible working arrangements are approved by employers or that they are rolled out consistently across Australian workplaces (O'Loughlin et al. 2017). This is important as the most commonly cited reason given by non-employed caregivers as to why they do not work is difficulty arranging flexible working hours (Gray et al. 2008). 
Despite the considerable contribution of the above studies to our understanding of the integration of paid work and unpaid caring, there remains a gap in our understanding of the availability, usage and barriers to accessing flexible or special working arrangements (SWA) conducive to caring responsibilities. We adopt the terminology SWA, consistent with ABS data collections and to avoid confusion with one component of SWA, flexible working hours. Previous studies have focused on either parents with care giving responsibilities, or carers whose recipient has an underlying health condition requiring assistance. In this paper, we examine these aspects of usage of SWA by gender in three population groups:

(1) primary carers, who provide the principal assistance for a person with a disability or long-term health condition,

(2) other carers, who also care for a person with a disability or long-term health condition, but do not provide principal care, and

(3) non-carers, who are defined by the Australian Bureau of Statistics (ABS) as all people who are not primary or other carers. Nonetheless, they may have care responsibilities and a need to access SWA, for example, parents and others (e.g. grandparents) with caring responsibilities for children.

Our interest is in understanding the ways in which people who care have access to, utilise or report barriers to arrangements that enable them to fulfil both their unpaid care work and paid work responsibilities. Specifically, with the availability of unique nationally representative data, we seek to answer three questions: (1) What is the level of availability of SWAs? (2) What is the prevalence of usage of SWAs specifically to care?, and (3) What are the reported barriers to usage of SWAs to care?

\section{Data and Methods}

Data for this study were sourced from the 2015 ABS Survey of Disability, Ageing and Carers (SDAC) conducted between July and December 2015 (ABS 2016c). Three populations were sampled using multi-stage sampling techniques. These consisted of persons living in private dwellings, in self-care retirement villages and in care accommodation. The module on the availability of SWA was administered to persons living in households. Of 31,957 households originally contacted, 25,555 fully responded, yielding a response rate of $80 \%$.

\subsection{Measurement of availability, usage and barriers}

Within the employment module of SDAC, a number of questions were asked regarding the availability, use and barriers to SWAs to support caring work. These questions were asked of people aged 15 years and over, living in households and employed, but excluding the self-employed.

Firstly, respondents were asked "Does your employer provide you with any of the following special working arrangements, regardless of whether you have used them or not?" A prompt card was then shown to the respondent, consisting of the following list:

- Paid leave (e.g. annual leave, maternity leave, sick leave) excluding carer's leave.

- Paid carer's leave

- Unpaid leave (excluding unpaid carer's leave) 
- Unpaid carer's leave

- Flexible working hours

- Rostered day off

- Working from home

- Shift work

- Casual work

- Part time work

- Informal arrangement with employer

- Other (specify)

- No special working arrangements available

- Don't know.

For those indicating the availability of SWA, a follow up question was asked: "Of those special working arrangements you have mentioned, have you used any to help look after someone in the last six months?" Respondents then indicated the SWA (from the list above) used to facilitate caring responsibilities and whether there was any unmet need for further access to SWA. For those who used SWA and indicated a barrier to further access, and those who could not access SWA for caring needs at all, a prompt card was used to illicit reasons for this barrier, including:

- Applied or asked but was refused

- Do not have adequate working arrangements

- Didn't apply as thought they would say no anyway

- Nature of work makes using flexible working arrangements difficult

- Work commitments

- Not paid for time off (e.g., casual/shift worker)

- Subtle or other pressure from bosses or other workers

- Not enough paid leave left or available

- Anything else (specify).

\subsection{Measurement of Carer Status}

Using these questions, we develop measures of the availability, usage and barriers to access SWA specifically for caring responsibilities. Using measures of carer status available in SDAC, we examine variations in availability, usage and barriers to SWA reported by (1) primary carers, (2) other carers and (3) persons not defined by the ABS as carers, but nonetheless have caregiving responsibilities. Specifically, a primary carer is defined by the ABS as "a person who provides the most informal assistance, in terms of help of supervision, to a person with one or more disabilities, with one or more of the core activities of mobility, self-care or communication" (ABS 2016a). Other carers are 
defined as one who "provides informal assistance with one or more of the core activity tasks but has not been identified as the person that provides the most informal assistance" (ABS 2016a). Thus, both primary and other carers are defined with respect to the recipient of care having long term health conditions requiring assistance and care.

However, it is not only those who care for people with disabilities or long term health conditions who utilise SWA with the specific intent of caring, albeit they are not carers as defined by the ABS. This group includes those who have care obligations to others not identified as primary or other carers such as parents with care responsibilities for temporarily sick children or other family members. Our analysis seeks to provide population level prevalence of the use of SWA to care, thus all three caring categories are included in the following stratified analysis.

\section{Results}

Figure 1 displays our framework for understanding the availability, usage and barriers to SWA for caring using the SDAC data. Of the full sample of employed people living in households ( $n=26,529)$, about $94 \%$ report access to at least one type of SWA ( $n=25,094)$. Of this group, about $22 \%$ have used SWA to care in the last 6 months ( $n=5,803)$. Of those who have used SWA, about $15 \%$ wanted to use additional SWA to care in the previous 6 months, but faced barriers to do so $(n=891)$. Of the 19,291 employed people who did not use SWA to care, a small minority wanted to use SWA to care but couldn't (1.2\% n=224).

\subsection{Availability of Special Working Arrangements}

Of the $94 \%$ reporting availability of SWA, there is considerable variation in the type of SWA provided (Table 1). Within the full working population, the most prevalent SWA is paid leave (76\%), followed by paid carers leave ( $48 \%)$, unpaid leave $(43 \%)$ and flexible working hours $(39 \%)$. When classified by carer status, primary or other carers are more likely to report access to informal arrangements, part time work or unpaid carers leave relative to non-carers. About $5.6 \%$ of workers were not aware of the availability of any SWA (responding 'no' or 'don't know'). These data also show important gender differentials with respect to carer status and perceived availability of SWA. Whereas the gender split for non-carers and other carers are relatively equal, just under $70 \%$ of all primary carers are female (68.3\%). Moreover, although the perceived availability by SWA is relatively consistent by gender, females (relative to males) are more likely to cite availability of casual work (32.2\% versus $21.5 \%$ ) or part time work (34.1\% versus $14.7 \%)$.

\subsection{Usage of Special Working Arrangements}

The availability of SWA, although important, is distinctly different from usage. Results in Table 2 classify SWA arrangements used in the previous 6 months specifically to care. There is a clear gradient in SWA usage to care by carer status. Approximately $64 \%$ of primary carers had used SWA in the previous 6 months, compared with $43 \%$ of other carers and about $19 \%$ of non-carers. Around $2 \%$ of primary and other carers wanted to use SWA to care but couldn't. When usage, as opposed to availability of SWA is considered, about $55 \%$ of non-carers and other carers are female, as are $70 \%$ of primary carers. 


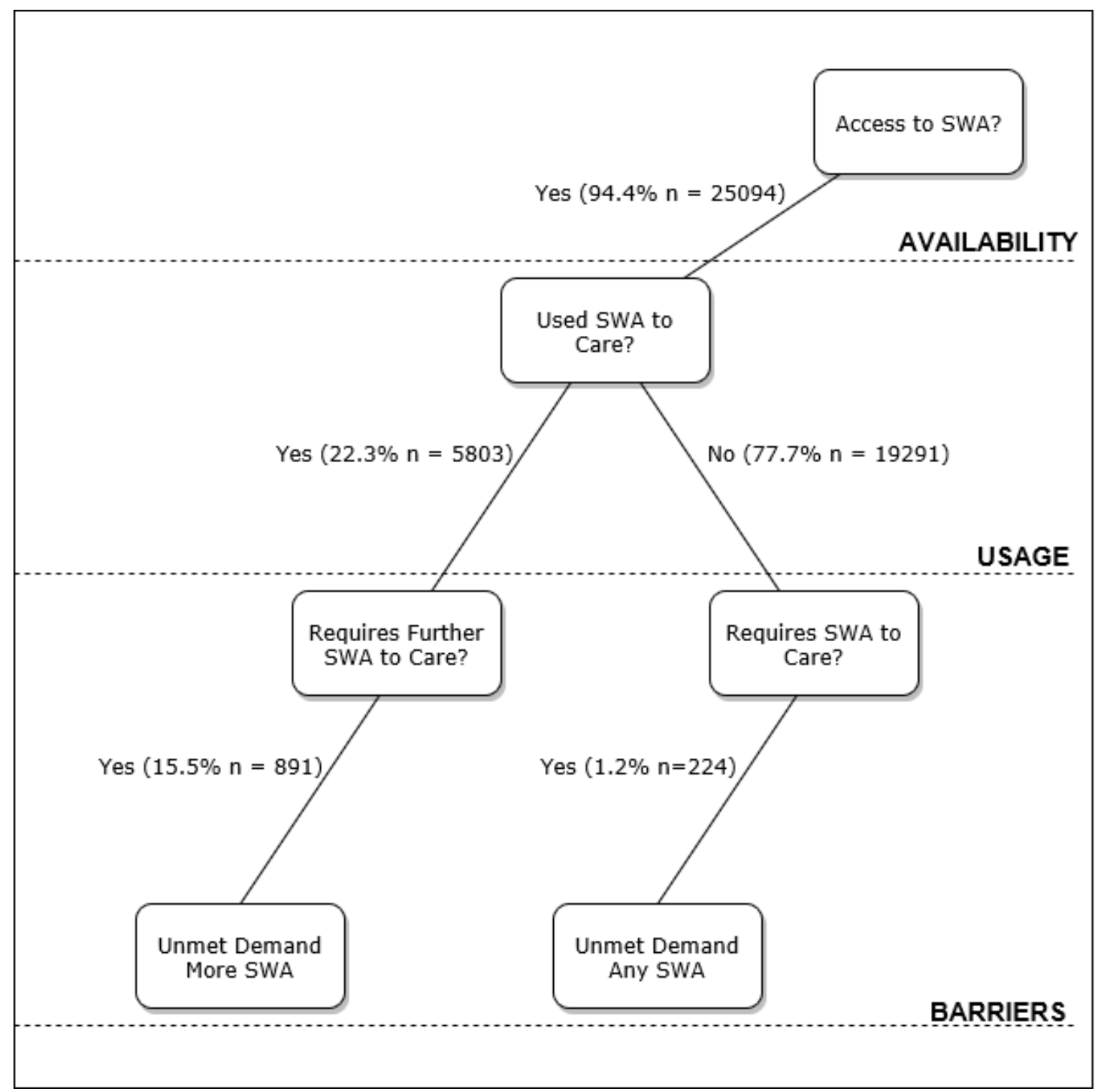

Figure 1: Framework of the availability, usage and barriers to SWA for caring Source: designed by the authors; data from ABS 2016c

Consistent with the data on availability (Table 1), the results in Table 2 show that paid leave (42\%) and paid carers leave (47\%) are the most commonly used SWA to care. About $10 \%$ of primary carers report unpaid leave, unpaid carers leave, casual work or part-time work SWA to care - which is higher than the rates of usage by non-carers. About one quarter of primary carers also cite use of flexible working hours to care (24\%).

Again, there is relative consistency in the likelihood of using different SWA to care by gender. For example, about $15.1 \%$ of males who have used SWA to care have used flexible work hours as have $17 \%$ of females. However, although rates of usage are similar for males and females, the usage of specific SWA to care is heavily skewed towards female workers. For example, around $80 \%$ of those using part-time work to care are female, regardless of carer status. Among primary carers specifically, around $80 \%$ of those using part-time work, casual work, or unpaid carers leave to care are female, regardless of carer status. 
Table 1: Availability of Special Working Arrangements (\%) by carer status and sex, 2015

\begin{tabular}{|c|c|c|c|c|c|c|c|c|c|c|c|c|c|c|c|c|c|c|}
\hline & \multicolumn{4}{|c|}{ Males } & \multicolumn{4}{|c|}{ Females } & \multicolumn{6}{|c|}{ Total } & \multicolumn{4}{|c|}{ \% Female } \\
\hline & & arer Statu & & Total & & arer Statu & & Total & & Carer Sta & atus & & & Total & & Carer Statı & & Total \\
\hline Access to SWA & No & Primary & Other & & No & Primary & Other & & No- & Primary & & Other & & & No- & Primary & Other & \\
\hline No & 4.2 & 2.9 & 3.9 & 4.1 & 3.6 & 3.0 & 4.4 & 3.7 & 3.9 & 2.9 & & 4.2 & & 3.9 & 45.6 & 68.5 & 53.6 & 46.8 \\
\hline Don't Know & 2.0 & 1.0 & 2.8 & 2.0 & 1.5 & 0.3 & 0.8 & 1.4 & 1.7 & 0.5 & $* *$ & 1.8 & & 1.7 & 42.7 & 40.8 & 22.5 & 40.9 \\
\hline Yes & 93.9 & 96.1 & 93.2 & 93.9 & 94.8 & 96.7 & 94.8 & 94.9 & 94.3 & 96.5 & $* *$ & 94.0 & & 94.4 & 49.2 & 68.4 & 50.9 & 49.9 \\
\hline Total & 100.0 & 100.0 & 100.0 & 100.0 & 100.0 & 100.0 & 100.0 & 100.0 & 100.0 & 100.0 & & 100.0 & & 100.0 & 48.9 & 68.3 & 50.5 & 49.7 \\
\hline \multicolumn{19}{|c|}{ Type of SWA has access to: } \\
\hline Paid leave & 79.9 & 72.1 & 81.1 & 79.8 & 73.1 & 70.0 & 76.6 & 73.3 & 76.6 & 70.7 & $* *$ & 78.8 & $*$ & 76.6 & 47.0 & 67.7 & 49.5 & 47.8 \\
\hline Paid carer's leave & 47.7 & 43.5 & 50.4 & 47.8 & 48.2 & 48.8 & 54.8 & 48.8 & 47.9 & 47.1 & & 52.7 & $* * *$ & 48.3 & 49.5 & 70.8 & 53.0 & 50.4 \\
\hline Unpaid leave & 42.7 & 41.0 & 42.2 & 42.6 & 43.7 & 44.0 & 48.1 & 44.1 & 43.2 & 43.1 & & 45.2 & $* *$ & 43.3 & 49.8 & 69.9 & 54.2 & 50.8 \\
\hline Unpaid carer's & 29.2 & 30.0 & 32.4 & 29.5 & 30.3 & 34.5 & 37.0 & 31.1 & 29.8 & 33.1 & $*$ & 34.8 & $* *$ & 30.3 & 50.1 & 71.3 & 54.2 & 51.2 \\
\hline Flexible working & 37.2 & 42.6 & 37.8 & 37.3 & 41.1 & 44.9 & 45.1 & 41.6 & 39.1 & 44.2 & $* * *$ & 41.5 & $* * *$ & 39.5 & 51.7 & 69.5 & 55.3 & 52.6 \\
\hline Rostered day off & 24.6 & 23.7 & 25.7 & 24.6 & 20.1 & 15.0 & 23.0 & 20.1 & 22.4 & 17.7 & $* *$ & 24.3 & $*$ & 22.4 & 44.2 & 57.7 & 48.1 & 44.9 \\
\hline Working from & 19.0 & 20.3 & 19.9 & 19.1 & 17.3 & 18.4 & 20.1 & 17.6 & 18.2 & 19.0 & & 20.0 & $* *$ & 18.3 & 47.0 & 66.2 & 51.1 & 48.0 \\
\hline Shift work & 17.3 & 13.7 & 19.4 & 17.4 & 14.9 & 10.9 & 16.1 & 14.8 & 16.1 & 11.7 & $* * *$ & 17.7 & & 16.1 & 45.4 & 63.2 & 46.2 & 45.9 \\
\hline Casual work & 21.6 & 21.9 & 20.0 & 21.5 & 32.4 & 30.3 & 31.1 & 32.2 & 26.9 & 27.6 & & 25.7 & & 26.8 & 59.2 & 74.9 & 61.8 & 59.9 \\
\hline Part time work & 14.5 & 19.7 & 15.9 & 14.7 & 32.8 & 46.3 & 41.5 & 34.1 & 23.5 & 37.9 & $* * *$ & 29.0 & $* * *$ & 24.4 & 68.6 & 83.6 & 73.0 & 69.8 \\
\hline Informal & 9.2 & 14.9 & 11.8 & 9.5 & 9.7 & 16.1 & 15.3 & 10.4 & 9.4 & 15.8 & $* * *$ & 13.5 & $* * *$ & 10.0 & 50.5 & 70.1 & 57.4 & 52.2 \\
\hline Other & 1.0 & 1.7 & 0.8 & 1.0 & 0.8 & 0.7 & 1.3 & 0.8 & 0.9 & 1.0 & & 1.1 & & 0.9 & 43.0 & 47.3 & 62.6 & 45.1 \\
\hline $\mathrm{n}=$ & 11974 & 263 & 1120 & 13357 & 11456 & 558 & 1158 & 13172 & 23430 & 821 & & 2278 & & 26529 & NA & NA & NA & NA \\
\hline$\%$ total (weighted) & 89.9 & 1.9 & 8.2 & 100.0 & 87.4 & 4.1 & 8.5 & 100.0 & 88.7 & 3.0 & & 8.4 & & 100.0 & 48.9 & 68.3 & 50.5 & 49.7 \\
\hline
\end{tabular}

Source: ABS $2016 \mathrm{c}$

Notes: SWA Special Working Arrangements; No- base case for tests of proportions for the Total category; ${ }^{*} p<0.05 * * p<0.01 * * * p<0.001 ; \%$ Females percentage in each discrete category that are female; NA Not Applicable. 
Table 2: Whether used Special Working Arrangements to care (\%) by carer status and sex, 2015.

\begin{tabular}{|c|c|c|c|c|c|c|c|c|c|c|c|c|c|c|c|c|c|c|c|c|}
\hline \multirow[b]{3}{*}{ Used SWA to care? } & \multicolumn{4}{|c|}{ Males } & \multicolumn{6}{|c|}{ Females } & \multicolumn{6}{|c|}{ Total } & \multicolumn{4}{|c|}{ \% Female } \\
\hline & \multicolumn{3}{|c|}{ Carer Status } & \multirow[t]{2}{*}{ Total } & \multicolumn{4}{|c|}{ Carer Status } & \multirow[t]{2}{*}{ Total } & \multirow[b]{2}{*}{$n=$} & \multicolumn{4}{|c|}{ Carer Status } & & \multirow[t]{2}{*}{ Total } & \multicolumn{3}{|c|}{ Carer Status } & \multirow[t]{2}{*}{ Total } \\
\hline & No & Primary & Other & & $n=$ & No & Primary & Other & & & No- & Primary & & Other & & & No- & Primary & Other & \\
\hline Wanted to, but couldn't & 0.7 & 2.7 & 1.1 & 0.8 & 103 & 0.9 & 2.3 & 1.9 & 1.0 & 121 & 0.8 & 2.4 & $* *$ & 1.5 & $* *$ & 0.9 & 53.7 & 65.0 & 63.1 & 55.9 \\
\hline No need & 81.8 & 36.1 & 58.9 & 79.0 & 9838 & 77.1 & 31.9 & 49.9 & 72.9 & 9019 & 79.5 & 33.2 & $* * *$ & 54.3 & $* * *$ & 76.0 & 47.8 & 65.7 & 46.8 & 48.0 \\
\hline Don't Know & 0.8 & 0.8 & 1.4 & 0.8 & 110 & 0.7 & 0.2 & 0.8 & 0.7 & 100 & 0.8 & 0.4 & $* *$ & 1.1 & & 0.8 & 47.0 & 35.6 & 38.1 & 45.7 \\
\hline Yes, Used & 16.7 & 60.5 & 38.5 & 19.3 & 2503 & 21.3 & 65.7 & 47.4 & 25.4 & 3300 & 19.0 & 64.0 & $* * *$ & 43.0 & $* * *$ & 22.3 & 55.3 & 70.2 & 56.1 & 56.8 \\
\hline Total & 100 & 100 & 100 & 100 & 12554 & 100 & 100 & 100 & 100 & 12540 & 100 & 100 & & 100 & & 100 & & & & \\
\hline \multicolumn{21}{|c|}{ Type of SWA used to care: } \\
\hline Paid leave & 42.2 & 42.4 & 42.0 & 42.2 & 1019 & 43.3 & 37.4 & 37.1 & 41.7 & 1326 & 42.8 & 38.9 & & 39.3 & $* *$ & 41.9 & 56.0 & 67.5 & 53.1 & 56.5 \\
\hline Paid carer's leave & 48.5 & 40.4 & 49.6 & 48.2 & 1218 & 46.1 & 42.0 & 50.9 & 46.4 & 1566 & 47.2 & 41.5 & $*$ & 50.3 & & 47.2 & 54.1 & 71.0 & 56.7 & 55.8 \\
\hline Unpaid leave & 4.3 & 9.7 & 6.6 & 5.0 & 123 & 7.8 & 9.6 & 7.7 & 8.0 & 246 & 6.2 & 9.6 & $*$ & 7.3 & & 6.7 & 69.4 & 69.9 & 59.9 & 67.8 \\
\hline Unpaid carer's & 1.9 & 7.0 & 5.7 & 2.8 & 65 & 3.4 & 10.4 & 6.7 & 4.7 & 146 & 2.7 & 9.4 & $* * *$ & 6.2 & $* * *$ & 3.9 & 68.5 & 77.8 & 60.0 & 68.3 \\
\hline Flexible working & 14.5 & 25.8 & 16.4 & 15.5 & 375 & 15.1 & 24.6 & 20.7 & 17.0 & 553 & 14.8 & 25.0 & $* * *$ & 18.8 & $* *$ & 16.3 & 56.4 & 69.2 & 61.7 & 59.1 \\
\hline Rostered day off & 4.7 & 13.0 & 10.8 & 6.2 & 134 & 2.7 & 3.9 & 6.1 & 3.4 & 98 & 3.6 & 6.6 & $*$ & 8.1 & $* * *$ & 4.6 & 41.5 & 41.3 & 41.9 & 41.6 \\
\hline Working from & 9.7 & 13.3 & 8.7 & 9.7 & 224 & 7.8 & 7.5 & 7.2 & 7.6 & 241 & 8.6 & 9.2 & & 7.9 & & 8.5 & 49.9 & 56.8 & 51.3 & 50.7 \\
\hline Shift work & 1.4 & 2.0 & 1.3 & 1.4 & 33 & 1.0 & 1.2 & 1.2 & 1.1 & 35 & 1.2 & 1.4 & & 1.2 & & 1.2 & 48.3 & 58.3 & 53.5 & 50.2 \\
\hline Casual work & 4.1 & 7.1 & 4.7 & 4.4 & 101 & 6.3 & 12.7 & 6.0 & 6.9 & 212 & 5.3 & 11.0 & $* * *$ & 5.4 & & 5.8 & 65.4 & 80.7 & 61.9 & 67.4 \\
\hline Part time work & 1.3 & 5.5 & 1.6 & 1.6 & 45 & 6.2 & 11.6 & 4.8 & 6.6 & 219 & 4.0 & 9.8 & $* * *$ & 3.4 & & 4.4 & 85.3 & 83.3 & 78.9 & 84.2 \\
\hline Informal & 3.5 & 7.2 & 5.4 & 4.0 & 90 & 3.0 & 6.9 & 3.2 & 3.4 & 106 & 3.2 & 7.0 & $*$ & 4.2 & & 3.7 & 51.4 & 69.2 & 43.1 & 52.8 \\
\hline Other & 0.7 & 1.6 & 0.0 & 0.6 & 11 & 0.3 & 0.0 & 0.6 & 0.3 & 9 & 0.5 & 0.5 & & 0.3 & & 0.5 & 36.6 & 0.0 & 100.0 & 40.8 \\
\hline
\end{tabular}

Source: ABS 2016c

Notes: SWA Special Working Arrangements; No- base case for tests of proportions for the Total category; ${ }^{*} p<0.05 * * p<0.01 * * * p<0.001 ; \%$ Females percentage in each discrete category that are female; $n=$ unweighted sample count. 


\subsection{Barriers to Special Working Arrangements}

Referring back to Figure 1, of the 5,803 workers who indicated they had used SWA to care, about $15.5 \%(n=891)$ reported they wanted to use more but were unable to. This group were asked what SWA they wanted to use but couldn't (Table 3). Once more, paid leave and paid carers leave were the most likely SWA that workers wished to make more use of to care. Interestingly, there is little difference in the SWA type needed by carer status. However, primary carers (24.6\%) and other carers (21.8\%) were more likely to report a barrier to further use of SWA, relative to non-carers (13.1\%). Types of SWA needed are relatively consistent by gender. However, male other carers are more likely to cite the need for rostered day off ( $11.8 \%$ versus $2.5 \%)$ whereas female other carers are more likely to cite the need for paid leave (34.7\% versus $23.9 \%$ ). Again, due simply to the overrepresentation of female primary carers, about $70 \%$ of primary carers with unmet demand for further access to SWA were female.

Results in Table 4 report the reasons for barriers to using SWA to care, for two groups. The first 'additional use of SWA' are the $15.5 \%$ ( $n=891)$ group who used SWA, but wanted to use more and couldn't. Regardless of carer status, the main reasons for not using further SWA to care were 'not enough paid leave left' (29\%), 'work commitments (23.4\%) and 'nature of work makes using flexible working arrangements difficult' (16\%). Although in the minority, it is concerning to note that $8 \%$ cited 'subtle or other pressures from bosses or other workers' or 'didn't apply as thought they would say no anyway'. Primary carers were slightly more likely to cite this later reason (12\%) compared with non-carers.

The second group in Table 4, titled 'Any use of SWA' are those who had SWA available to them, but could not use it to care at all. Referring back to Figure 1 , this is the smaller group of $1.2 \%(n=224)$ of those who didn't use SWA to care. As with the previous group, about 1 in 4 report 'work commitments' as the main reason for not using SWA to care (24.3\%). Approximately $15 \%$ reported 'Didn't apply as thought they would say no', 'nature of work makes using flexible working arrangements difficult' or 'subtle or other pressure from bosses or other workers'. Due to the small sample size of this population, there are few statistically significant differences in reasons given for barriers to any use of SWA by carer status. Moreover, there is insufficient sample size to disaggregate this table by gender. 
Table 3: Unmet demand for further access to Special Working Arrangements to care (\%) by carer status and sex, 2015.

\begin{tabular}{|c|c|c|c|c|c|c|c|c|c|c|c|c|c|c|c|c|c|c|c|}
\hline \multirow[b]{3}{*}{ More use of SWA? } & \multicolumn{4}{|c|}{ Males } & \multicolumn{6}{|c|}{ Females } & \multicolumn{5}{|c|}{ Total } & \multicolumn{4}{|c|}{$\%$ Female } \\
\hline & \multicolumn{3}{|c|}{ Carer Status } & \multirow[t]{2}{*}{ Total } & \multirow[b]{2}{*}{$\mathrm{n}=$} & \multicolumn{3}{|c|}{ Carer Status } & \multirow[t]{2}{*}{ Total } & \multirow[b]{2}{*}{$\mathrm{n}=$} & \multicolumn{4}{|c|}{ Carer Status } & \multirow[t]{2}{*}{ Total } & \multicolumn{3}{|c|}{ Carer Status } & \multirow[t]{2}{*}{ Total } \\
\hline & No & Primary & Other & & & No & Primary & Other & & & No- & Primary & & Other & & No- & Primary & Other & \\
\hline No & 83.2 & 66.2 & 69.5 & 79.9 & 2010 & 84.6 & 69.6 & 75.9 & 81.6 & 2694 & 83.9 & 68.6 & $* * *$ & $73.1 * *$ & 80.9 & 55.9 & 71.3 & 58.4 & 57.4 \\
\hline Don't Know & 3.1 & 8.3 & 5.9 & 3.9 & 96 & 2.8 & 6.3 & 4.4 & 3.4 & 112 & 2.9 & 6.9 & $* *$ & $5.1 * *$ & 3.6 & 52.6 & 64.2 & 49.1 & 53.8 \\
\hline Yes & 13.7 & 25.5 & 24.5 & 16.2 & 397 & 12.6 & 24.1 & 19.7 & 15.0 & 494 & 13.1 & 24.5 & $* * *$ & $21.8 * * *$ & 15.5 & 53.5 & 69.1 & 50.7 & 55.0 \\
\hline Total & 100 & 100 & 100 & 100 & 2503 & 100 & 100 & 100 & 100 & 3300 & 100 & 100 & & 100 & 100 & & & & \\
\hline \multicolumn{20}{|c|}{ Type of SWA needed } \\
\hline Paid leave & 36.6 & 36.1 & 23.9 & 33.4 & 131 & 35.0 & 32.5 & 34.7 & 34.5 & 163 & 35.7 & 33.6 & & 29.4 & 34.0 & 52.4 & 66.8 & 60.0 & 55.8 \\
\hline Paid carer's leave & 42.6 & 37.4 & 39.8 & 41.4 & 170 & 42.6 & 44.8 & 44.1 & 43.3 & 221 & 42.6 & 42.5 & & 42.0 & 42.4 & 53.5 & 72.8 & 53.3 & 56.1 \\
\hline Unpaid leave & 2.0 & 10.1 & 5.9 & 3.7 & 15 & 5.5 & 2.4 & 4.6 & 4.8 & 25 & 3.9 & 4.8 & & 5.3 & 4.3 & 76.5 & 34.8 & 44.4 & 61.3 \\
\hline Unpaid carer's & 1.8 & 8.1 & 1.4 & 2.3 & 9 & 3.9 & 10.1 & 3.9 & 5.0 & 19 & 2.9 & 9.5 & & 2.7 & 3.8 & 71.3 & 73.6 & 74.5 & 72.6 \\
\hline Flexible working & 10.4 & 4.0 & 8.5 & 9.3 & 43 & 7.2 & 13.5 & 8.2 & 8.5 & 48 & 8.7 & 10.6 & & 8.3 & 8.9 & 44.4 & 88.2 & 49.9 & 52.7 \\
\hline Rostered day off & 1.0 & 6.4 & 11.8 & 4.2 & 13 & 1.0 & 2.1 & 2.5 & 1.5 & 8 & 1.0 & 3.4 & & $7.1^{* *}$ & 2.7 & 52.7 & 42.1 & 18.0 & 30.3 \\
\hline Working from & 8.3 & 4.5 & 11.8 & 8.8 & 35 & 6.6 & 6.2 & 4.7 & 6.2 & 32 & 7.4 & 5.7 & & 8.2 & 7.4 & 47.7 & 75.7 & 29.3 & 46.0 \\
\hline Shift work & 0.5 & 2.8 & 1.3 & 0.9 & 4 & 0.2 & 1.3 & 0.0 & 0.3 & 2 & 0.3 & 1.8 & & 0.7 & 0.6 & 26.0 & 50.5 & 0.0 & 29.4 \\
\hline Casual work & 2.5 & 1.2 & 5.6 & 3.2 & 12 & 4.7 & 2.8 & 4.7 & 4.4 & 18 & 3.7 & 2.3 & & 5.1 & 3.8 & 67.9 & 84.4 & 46.7 & 62.8 \\
\hline Part time work & 0.0 & 2.1 & 1.4 & 0.5 & 3 & 1.1 & 3.4 & 1.8 & 1.6 & 13 & 0.6 & 3.0 & & 1.6 & 1.1 & 100.0 & 78.4 & 57.6 & 78.7 \\
\hline Informal & 1.5 & 0.7 & 1.1 & 1.3 & 6 & 1.7 & 1.7 & 0.3 & 1.4 & 8 & 1.6 & 1.4 & & 0.7 & 1.4 & 56.2 & 84.0 & 20.2 & 56.0 \\
\hline Other & 0.2 & 0.0 & 0.0 & 0.1 & 1 & 0.1 & 0.0 & 0.0 & 0.0 & 1 & 0.1 & 0.0 & & 0.0 & 0.1 & 27.5 & 0.0 & 0.0 & 27.5 \\
\hline
\end{tabular}

Source: ABS $2016 \mathrm{c}$

Notes: SWA Special Working Arrangements; No- base case for tests of proportions for the Total category; ${ }^{*} p<0.05 * * p<0.01 * * * p<0.001 ; \%$ Female percentage in each discrete category that are female; $n=$ unweighted sample count. 
Table 4: Reasons for barrier to additional or any use of Special Working Arrangements (\%) by carer status, 2015.

\begin{tabular}{|c|c|c|c|c|c|c|c|c|c|c|}
\hline \multirow[b]{3}{*}{ Reason for Barrier } & \multicolumn{5}{|c|}{ Additional Use of SWA [1] } & \multicolumn{5}{|c|}{ Any Use of SWA [2] } \\
\hline & \multicolumn{4}{|c|}{ Carer Status } & \multirow[t]{2}{*}{ All } & \multicolumn{3}{|c|}{ Carer Status } & \multirow{2}{*}{\multicolumn{2}{|c|}{ All }} \\
\hline & No & Primary & & Other & & No & Primary & Other & & \\
\hline Applied or asked but was refused & 5.4 & 8.1 & & 4.0 & 5.4 & 8.0 & 15.0 & 8.6 & & 8.6 \\
\hline Do not have adequate working arrangements & 9.2 & 6.2 & & 10.1 & 9.0 & 5.9 & 6.6 & 15.0 & & 7.2 \\
\hline Didn't apply as thought they would say no anyway & 6.7 & 11.9 & $*$ & 9.0 & 7.9 & 15.0 & 23.9 & 11.1 & & 15.1 \\
\hline Concern that using arrangements would be viewed poorly & 0.9 & 1.0 & & 0.0 & 0.7 & 0.1 & 0.0 & 3.7 & & 0.6 \\
\hline Nature of work makes using flexible working arrangements & 15.2 & 16.5 & & 16.9 & 16.0 & 14.7 & 15.2 & 21.8 & & 15.5 \\
\hline Work commitments & 22.3 & 30.6 & \# & 22.0 & 23.4 & 24.9 & 33.9 & 15.0 & & 24.3 \\
\hline Not paid for time off (e.g. casual/shift worker) & 6.6 & 5.2 & & 8.2 & 6.8 & 8.8 & 9.9 & 21.0 & \# & 10.6 \\
\hline Subtle or other pressure from bosses or other workers & 7.0 & 12.1 & & 8.1 & 8.0 & 14.1 & 7.3 & 9.9 & & 13.0 \\
\hline Not enough paid leave left or available & 31.0 & 26.2 & & 25.2 & 29.0 & 6.7 & 18.3 & 10.8 & & 8.2 \\
\hline Own circumstances made use of arrangements unfeasible & 1.3 & 0.0 & $* *$ & 2.9 & 1.5 & 3.3 & 0.9 & 0.0 & $*$ & 2.7 \\
\hline Anything else & 3.9 & 3.4 & & 3.7 & 3.8 & 7.7 & 7.0 & 8.2 & & 7.7 \\
\hline Don't know & 5.8 & 5.0 & & 6.5 & 5.9 & 8.9 & 4.9 & 0.8 & & 7.5 \\
\hline $\mathrm{n}$ & 573 & 128 & & 190 & 891 & 170 & 18 & 36 & & 224 \\
\hline
\end{tabular}

Source: ABS 2016c

Notes: SWA Special Working Arrangements; No- base case for tests of proportions; $\# p<0.10 * p<0.05 * * p<0.01 * * * p<0.001 ; n=$ unweighted sample count; [1] Population of those who had already used SWA, but have unmet demand for further use of SWA to care; [2] Population of those who have not used SWA and wanted to use them to care. 


\section{Discussion}

The clear majority of respondents reported the availability of SWA in their workplace (94\%) and indeed, carers were slightly more likely to cite awareness of flexible working hours, unpaid carers leave, part time work and informal arrangements with their employer than non-carers. It may be that carers are more aware of certain SWA, because of their personal requirement to have them as a necessary condition of employment. That is, they self-select into positions with SWA that enable a continuation of unpaid caring responsibilities. A further explanation is that they are more aware of SWA regardless of occupation or industry, simply because they have a greater need for SWA than non-carers.

SWA are taken up by a majority of primary carers $(64 \%)$ and $43 \%$ of other carers (within the last six months) with paid leave and paid carers leave being the most used arrangements. However, these arrangements are not perceived as sufficient for $15.5 \%$ of the workforce surveyed, with primary carers $(24.6 \%)$ and other carers $(21.8 \%)$ more likely to report barriers to further use of SWA than non-carers (13.1\%). The majority of unmet demand is by those who already use it, but need to make more use of it.

Supporting previous research, our results underscore the gendered nature of care giving responsibilities in Australia and show the interaction with SWA usage. Almost $70 \%$ of employed primary carers using SWA to care were female, compared with $55 \%$ of other and non-carers. Around $80 \%$ of those using part-time work to care were female, regardless of carer status. Among primary carers specifically, around $80 \%$ of those using part-time work, casual work, or unpaid carers leave to care are female, regardless of carer status. While there has been considerable attention on the needs of mothers for flexible work arrangements in Australia, our results also highlight the un-met needs of workers who provide care for those with a disability and long-term health problems. Women also overwhelming attend to these various care needs, altering their work schedules to do so and experiencing negative consequences in terms of career and financial penalties.

These findings regarding carers are supported by a growing body of research and data points to both the gendered use of SWAs in the general population (i.e. not just carers), including part-time work, and the gap between availability of SWAs and their uptake. McDonald et al.(2005 p.41) argue that men, and women in managerial roles, are less likely to use SWAs due to lack of managerial support, perceptions of negative career consequences, lack of co-worker support and time pressures at work. In a study of a large telecommunications company, Cooper and Baird (2015) found that use of Australia's legislative right to request 'flexible work arrangements' was heavily dominated by working mothers when they were supported by their line managers. In a comparative review, Thornthwaite (2004) shows that working mothers, more than fathers, in Australia prefer part-time work and access to flexible hours to accommodate the gendered division of labour in the home, school hours and lack of suitable child care.

For both male and female carers, the main barrier that carers face is insufficient paid leave and/or work commitments (requiring them to put the demands of the workplace over their need for time off to care) but to a lesser extent they face subtle or real pressure from others not to apply for leave or other flexible work arrangements. Around $5 \%$ of those who wanted to access further SWA for care and $9 \%$ of those who wanted to access any SWA cited a rejection by the employer. 
Under the National Employment Standards, employers can refuse a request on 'reasonable business grounds'. These grounds are very broad and include:

- Requested arrangements are too costly for the employer

- There is no capacity to change the current working arrangements

- Impractical to change extant working arrangements

- The requested arrangement would result in a 'significant loss of efficiency or productivity'

- The requested arrangement would be likely to have a significant negative impact on customer service.

In the case of a refused request, the employee can seek assistance from the Fair Work Commission. However, the Fair Work Commission does not have the legislative power to direct an employer to agree to the employee's request. Therefore, there is limited right to appeal the employers' refusal. Moreover, there are numerous caveats to those eligible to access flexible arrangements under the Act. For example, workers must have been employed for at least 12 months before making a request for flexible working arrangements.

Stronger legislative controls have recently come into force following a ruling from the full bench of the Fair Work Commission. From 1 December 2018, employers must provide a detailed written response outlining the reason for the refused request. In considering the request, employers must consider (1) the needs of the employee, (2) consequences for the employee is changes in working arrangements aren't made, as well as (3) Reasonable business grounds for refusing the employees request (FWO 2019).

Rather than being considered as part of labour market policy alone, access to flexible working arrangements for carers should be seen as an integral part of the health system supporting Australia's ageing population and those with underlying health conditions (Yeandle and Cass 2013; Vecchio 2015). Indeed, in Vecchio's (2015) important study of the labour force behaviour of those residing with a person with a disability, they argue "Policy makers need to aggressively challenge current workforce programs to encourage employers to provide more flexible work arrangements. Workforce programs that allow family members opportunities to provide adequate caregiving and financial support to ill relatives are fundamental to the sustainability of health care programs" (p. 9).

There is currently no overarching policy framework in Australia that addresses this issue. There was a National Carer Strategy in Australia (2011) but this was not adopted by the current government. The previous Labor Federal government commenced the implementation of a National Carer Action Plan 2011-2014, which had a range of strategies for improving the economic security of carers, including strategies for enabling workforce participation. However, the current Coalition government has restricted its focus to carers to carer support services accessible through the Carer Gateway (Department of Social Services 2017). With the role out of the National Disability Insurance Scheme (NDIS), early evidence suggests that carers employment prospects have not improved (Hamilton 2018). One possibility is to allow carers access to NDIS to support employment needs. As argued by Hamilton (2018) "This would be an important start in developing services that actually support carers to work - not just hoping that carers gain time for paid work by altering disability services". 
In interpreting the results from this study, it is important to note the limitations. First, data from the SDAC are cross-sectional and the measures are collected only for the employed. We cannot, for example, determine whether carers have ceased employment due to a lack of flexible working arrangements, although evidence suggests this may be the case (Austen et al. 2013). Secondly, our measure of the usage of SWA is retrospective, over a six month period only. Third, the analyses we present herein are descriptive. Further multivariable analysis is required, particularly of the industry, workplace and characteristics of carers reporting a barrier to accessing SWA to care.

\section{Conclusions}

With the ageing of the Australian population, there is a need for more family carers at the same time as for greater workforce participation, especially amongst women. This study suggests that to enable people to deliver their caregiving responsibilities and participate in the workforce, more paid leave is required as well as other SWA strategies that encourage employers to recognize and support carers in the workplace.

The business case for offering SWA is growing, with a number of large employers now offering 'flex for all'. McDonald et al. (2005 p. 38), citing a number of studies, outline the benefits for business as 'improving the retention or recruitment of skilled women, reducing absenteeism, increasing productivity and reducing hiring and retraining costs'. There are also numerous coted benefits to employees of being able to access SWAs. These include reduction in personal stressors and improvements in the mental and physical health of workers (McDonald et al. 2005 p. 39). Given that financial considerations are among the strongest unmet needs reported by Australian carers, improving the fit between paid and unpaid work is one strategy by which improvements in economic wellbeing can be achieved (Temple and Dow 2018).

More generally, greater awareness of the societal and economic benefits of caring are needed so that workplace arrangements are not just seen as an individual benefit and carers can feel legitimized in accessing SWA. Stronger legislative arrangements are also required to enforce employers to grant carers flexible working arrangements. Recent strengthening of legislative controls have recently come into force following a ruling from the full bench of the Fair Work Commission and will require evaluation with further data collections. Another possible solution would be government subsidies to enable carers to take more leave. Whatever policy and practice levers are put in place, thorough evaluation is required to improve knowledge of which SWA are effective in enabling carer workforce participation.

\section{Key messages}

- Population ageing and demographic change are increasing the number of unpaid informal carers who face barriers to labour market attachment at the same time that the Australian labour market is projected to experience lower growth and reduced participation.

- Many Australian carers face barriers to employment, as well as barriers to underemployment by those already employed. Although the vast majority of workers are aware of SWA and about 1 in 5 have used SWA to care, almost 1 in 4 primary carers and 1 in 5 other carers faced barriers to using SWA to care. 
- The main barriers faced by employed carers included insufficient paid leave and/or work commitments (requiring them to put the demands of the workforce over their need for time off to care).

- The results also underscore the gendered nature of care responsibilities in Australia. Almost $70 \%$ of employed primary carers using SWA to care were female, compared with $55 \%$ of other and non-carers. Among primary carers specifically, around $80 \%$ of those using part-time work, casual work, or unpaid carers leave to care were female.

- Stronger legislative arrangements are required to assist carers to access SWA.

\section{Acknowledgements}

Data for this study were made available to the authors by the Australian Bureau of Statistics (ABS). Jeromey Temple is funded by the Australian Research Council's Centre of Excellence in Population Ageing Research (CE1101029). The opinions expressed herein are those of the authors alone.

\section{References}

ABS (2016a) Disability, ageing and carers, Australia: Summary of findings. Catalogue No. 4430.0. Canberra: ABS. Available from: https://www.abs.gov.au/ausstats/abs@.nsf/mf/4430.0. Accessed May 2018.

ABS (2016b) A profile of carers in Australia. Information Sheet. Canberra: ABS. Available from: https://www.abs.gov.au/ausstats/abs@.nsf/Lookup/4430.0main+features602015. Accessed May 2018.

ABS (2016c) Microdata: Disability, Ageing and Carers, Australia, 2015. Catalogue No. 4430.0.30.002. Canberra: ABS.

Austen S and Ong R (2013) The effects of ill health and informal care roles on the employment retention of mid-life women: Does the workplace matter? Journal of Industrial Relations 55(5): 663-680.

Australian Treasury (2002) Intergenerational Report 2002-03. Canberra: Australian Government.

Australian Treasury (2007) Intergenerational Report. Canberra: Australian Government.

Australian Treasury (2010) Intergenerational Report. Australia to 2050: Future Challenges. Canberra: Australian Government.

Australian Treasury (2015) Intergenerational Report: Australia in 2055. Canberra: Australian Government.

Bittman M, Hill T and Thomson C (2007) The Impact of caring on informal carers' employment, income and earnings: a longitudinal approach. Australian Journal of Social Issues 42(2): 255-272.

Cooper R and Baird M (2015) Bringing the 'right to request' flexible working arrangements to life: from policies to practices. Employee Relations 37 (5): 568-581.

Cummins R, HughesJ, Tomyn A, Gibson J, Woerner J and Lai, LI. (2007) The wellbeing of Australians - carer health and wellbeing, in Australian Unity Wellbeing Index Surveys. Australian Centre on Quality of Life, Deakin University. Melbourne.

Deloitte Access Economics (2015) The economic value of informal care in 2015. Canberra: Deloitte Access Economics.

Department of Social Services (2017) Disability and Carers Carer Gateway. https://www.dss.gov.au/ourresponsibilities/disability-and-carers/programmes-services/for-carers/carer-gateway. Accessed 25 Nov 2017.

FWO (2018) Requests for flexible working arrangements and the National Employment Standards. Fair Work Ombudsman: Canberra. Available from: www.fairwork.gov.au. Accessed May 2018 
FWO (2019) Flexible Working Arrangements. Fair Work Ombudsman: Canberra. Available from: www.fairwork.gov.au. Accessed May 2019.

Gray M, Edwards B and Zmijewski N (2008) Caring and women's labour market participation. Family Matters 78: 28-35.

Hamilton M (2018) The NDIS hasn't made much difference to carers' opportunities for paid work. The Conversation. Available from: https://theconversation.com/the-ndis-hasnt-made-muchdifference-to-carers-opportunities-for-paid-work-98157. Accessed May 2019.

Hegewisch A and Gornick J (2011) The impact of work-family policies on women's employment: a review from OECD countries. Community, Work and Family 14(2): 119-138.

Hill T, Thomson C, Bittman M and Griffiths M (2008) What kinds of jobs help carers combine care and employment? Family Matters 80: 27-32.

Lilly M, Laporte A and Coyte P (2007) Labour market work and home care's unpaid caregivers: A systematic review of labor force participation rates, predictors of labor market withdrawal and hours of work. The Milbank Quarterly 85(4): 641-690.

McDonald P, Brown K and Bradley L (2005) Explanations for the provision-utilisation gap in work-life policy. Women in Management Review 20(1): 37-55.

McDonald P (2017) International migration and employment growth in Australia, 2011-2016. Australian Population Studies 1(1): 3-12.

Murray J (2005) Work and care: new legal mechanisms for adaptation. Labour and Industry 15(3): 67-87.

O'Loughlin K, Loh V, and Kendig H (2017) Carer characteristics and health, wellbeing and employment outcomes of older Australian baby boomers. Journal of Cross Cultural Gerontology 32(3): 339356.

Pavalko E and Henderson K (2006) Combining care work and paid work: do workplace policies make a difference? Research on Aging 28(3): 359-374.

Pinquart $M$ and Sorensen S (2003) Differences between caregivers and noncaregivers in psychological health and physical health: a meta-analysis. Psychology and Aging 18(2): 250-267.

Productivity Commission (2005) Economic Implications of an Ageing Australia. Research Report. Canberra: Productivity Commission.

Productivity Commission (2013) An Ageing Australia: Preparing for the Future. Research Report. Melbourne: Productivity Commission.

Schofield D, Cunich M, Shrestha R, Passey M, Kelly S, Tanton R, and Veermen L (2014) The impact of chronic conditions of care recipients on the labour force participation of informal carers in Australia: which conditions are associated with higher rates of non-participation in the labour force? BMC Public Health 14(1): 1-9.

Skinner N and Pocock B (2014) The Persistent Challenge: Living, Working and Caring in Australia in 2014. Centre for Work + Life, University of South Australia. Available from: https://www.unisa.edu.au/siteassets/episerver-6files/documents/eass/cwl/publications/awali 2014 national report final.pdf. Accessed May 2018.

Stata Corporation (2017) Stata/SE 15.0 for Windows 64 bit. College Station: Texas.

Temple J and Dow B (2018) The unmet support needs of carers of older Australians: prevalence and mental health. International Psychogeriatrics 30(12): 1849-1860.

Temple J and McDonald P (2017) Population ageing and the labour force: 2000-2015 and 2015-2030. Australasian Journal on Ageing 36(4): 264-270.

Thornthwaite L (2004) Working time and work-family balance: a review of employees' preferences. AsiaPacific Journal of Human Resources 42(2): 165-184. 
Vecchio N (2015) Labour force participation of families coping with a disabling condition. Economic Analysis and Policy 45(March): 1-10.

Yeandle S and Cass B (2013) Working carers of older people: steps towards securing adequate support in Australia and England. In Kroger T and Yeandle S (eds.) Combining Paid Work and Family Care: Policies and Experiences in International Perspective. Bristol: Polity Press; 71-87. 